\title{
Formal Schooling Influences Two- but Not Three-Dimensional Naming Skills
}

\author{
Alexandra Reis, $* \dagger$ Karl Magnus Petersson, ${ }^{*}$ Alexandre Castro-Caldas, $\ddagger$ and \\ Martin Ingvar* \\ *Department of Clinical Neuroscience, Cognitive Neurophysiology Research Group R2-01, \\ Karolinska Institutet, Karolinska Hospital, S-171 76 Stockholm, Sweden; †Área Departamental de \\ Psicologia, FCHS, Campus de Gambelas, Universidade do Algarve, 8000-117 Faro, Portugal; \\ and $¥$ Laboratório de Estudos de Linguagem, Centro de Estudos Egas Moniz, Hospital \\ de Santa Maria, 1600 Lisboa, Portugal
}

Published online August 17, 2001

\begin{abstract}
The modulatory influence of literacy on the cognitive system of the human brain has been indicated in behavioral, neuroanatomic, and functional neuroimaging studies. In this study we explored the functional consequences of formal education and the acquisition of an alphabetic written language on two- and three-dimensional visual naming. The results show that illiterate subjects perform significantly worse on immediate naming of two-dimensional representations of common everyday objects compared to literate subjects, both in terms of accuracy and reaction times. In contrast, there was no significant difference when the subjects named the corresponding real objects. The results suggest that formal education and learning to read and to write modulate the cognitive process involved in processing two- but not three-dimensional representations of common everyday objects. Both the results of the reaction time and the error pattern analyses can be interpreted as indicating that the major influence of literacy affects the visual system or the interaction between the visual and the language systems. We suggest that the visual system in a wide sense and/or the interface between the visual and the language system are differently formatted in literate and illiterate subjects. In other words, we hypothesize that the pattern of interactions in the functional-anatomical networks subserving visual naming, that is, the interactions within and between the visual and language processing networks, differ in literate and illiterate subjects. ๑ 2001 Elsevier Science
\end{abstract}

Key Words: literacy; illiteracy; visual naming; functional organization of the brain.

\section{INTRODUCTION}

The acquisition of alphabetic orthographic knowledge, that is, learning an alphabetic written language appears to influence the auditory-verbal language system in a nontrivial way and provide support for the hypothesis that the functional architecture of the brain is modulated by literacy (Petersson et al., 2000). Both behavioral

This work was supported by an FCT Grant (PRAXIS XXI/BPD/16314/98) for A.R. and both A.R. and K.M.P. were supported by grants from the Swedish Medical Research Council (8276). We also thank Dr. Maria Emília Santos for her assistance with the qualitative error analysis, Lennart Gransberg and Elisabet Fabian for their assistance in the construction of the technical equipment used in the experiment, and Joaquim Ferro for generous residential support.

Address correspondence and reprint requests to Alexandra Reis, Área Departamental de Psicologia, FCHS, Campus de Gambelas, Universidade do Algarve, 8000-117 Faro, Portugal. Fax: +351 289819 403. E-mail: aireis@ualg.pt. 
(Reis and Castro-Caldas, 1997) and functional neuroimaging data (Castro-Caldas et al., 1998) are consistent with this hypothesis. In addition, functional neuroimaging data indicate that there are relative interhemispheric activation differences in the posterior parietal cortex between the two literacy groups during immediate verbal repetition (Petersson et al., 1998). These interhemispheric differences appear to be paralleled by preliminary morphological findings indicating differences in the corpus callosum between literate and illiterate subjects. More specifically, the part of corpus callosum relaying the interhemispheric connections between the left and right posterior parietal cortices is larger in literate compared to illiterate subjects (Castro-Caldas et al., 1999). Taken together, these data can be interpreted as indicating that the acquisition of written language skills significantly modulates the spoken language system. Alternatively, the system for orthographic representations in literate subjects may support phonological processing as an auxiliary interactive network (Petersson et al. 2001). Additional data indicate that other cognitive functions are also influenced by formal education. Behavioral studies have demonstrated that the level of literacy (including illiteracy) influences the performance of several tasks often used in neuropsychological assessment (e.g., Lecours et al., 1987; Ostrosky et al., 1985; Ardila, Rosselli, \& Rosas, 1989; Rosselli, Ardila, \& Rosas, 1990; Manly et al., 1999). These include both visuospatial (Ardila et al., 1989; Matute et al., 2000; Ostrosky et al., 1991) and language tasks (Reis and Castro-Caldas, 1997). However, it is still unclear which processes and mechanisms mediate the influence of literacy. It is also unclear which parts of the cognitive system and which processing levels formal education and orthographic knowledge affect (for a recent review see Petersson et al., 2001).

Several behavioral studies have indicated that the level of literacy influences the performance when subjects name two-dimensional pictorial representations objects (Kremin et al., 1991; Manly et al., 1999; Reis et al., 1994; Rosselli et al., 1990). The performance on visual naming tasks is mainly dependent on the systems for visual recognition and language processing as well as the interaction between these systems (i.e., the interface between these systems). In this study we explore the functional consequences of literacy and formal education on two- (2D) and three-dimensional (3D) visual naming in a population living in a socioculturally relatively homogeneous fishermen community of southern Portugal. In parallel with the acquisition of orthographic knowledge in school, the literate subjects of this study population practiced the skill of interpreting schematic 2D representations. In other words, literate subjects are in general more practiced in coding/producing and decoding/interpreting 2D representations in terms of figurative/symbolic representations of real objects. In contrast, illiterate subjects have generally received relatively little systematic practice in interpreting conventional visuosymbolic representation. A previous preliminary study (Reis et al., 1994) indicated that the naming drawings of everyday objects was affected by the literacy level, while the level of literacy appeared not to influence the ability to name the same real objects. A limitation of this study is the fact that the 2D naming task was always presented before the 3D task. So, order effects (e.g., learning) may potentially explain the differential effect of literacy on 2D compared to $3 \mathrm{D}$ naming. In this study we return to this issue and investigate whether the difference in previous learning and experience in processing $2 \mathrm{D}$ information explain the differences in performance observed by Reis et al. (1994). To this end, we studied immediate naming of drawings, photos, and real objects in literate and illiterate subjects in a fully randomized study design. We also acquired and analyzed reaction time data from the correct responses as well as the pattern of incorrect responses qualitatively to further characterize the influence of literacy on these visual naming tasks. 


\section{MATERIAL AND METHODS}

\section{Stimulus}

Sixty-five object drawings (Appendix 1), each matched to a common everyday real object, were selected from the set by Snodgrass and Vanderwart (Snodgrass \& Vanderwart, 1980). Common everyday objects were selected to minimize possible vocabulary differences between subjects. Each drawing was closely matched with a similar real object. A digital camera (Nikon COOLPIX, $640 \times 480$ pixel resolution, 16-bit color depth) was used to photograph each object. The 65 items were divided into 3 sets (22/ $22 / 21$ ). The semantic categories were randomly distributed between the 3 sets under the (soft) constraint that different items from the same category were allocated to different sets. For each set of items, 3 corresponding lists of real objects $(\mathrm{O})$, photographs $(\mathrm{P})$, and line drawings $(\mathrm{D})$ were generated. The MacStim Software was used to display the D and P stimuli on a computer screen (Macintosh PowerBook 5300C, 8-bit color screen) and to register the reaction times (RTs). The whole experiment was run in a dark room. The same paced presentation paradigm was used for each presentation mode (PM: drawings, photos, and real objects). Each drawing and photograph was displayed for $5 \mathrm{~s}$ and voice detection equipment registered the RT between the onset of the display and the onset of the response. A similar procedure was used to register the $\mathrm{O}$ data. The real objects were displayed in a $50 \times 50 \times 50 \mathrm{~cm}$ black box, which was lit with a lamp for the same display time as in D and P (5 s/item). The RTs were registered in the same way as for $\mathrm{D}$ and $\mathrm{P}$ stimuli. The $5 \mathrm{~s}$ display time was sufficient to name the items in each PM (Goodglass et al., 1984; Levelt et al., 1998; Salmelin et al., 1994). All verbal responses were recorded with a tape recorder.

\section{Subjects}

In this study we further investigate the naturally occurring illiteracy in southern Portugal, that is, illiteracy for well-defined sociocultural reasons (Petersson et al., 2001; Reis et al., submitted). In order to minimize the interference of other cultural factors, the illiterate subjects and their matched controls were selected from a similar sociocultural background in a relatively homogeneous fishermen community of southern Portugal and most of the subjects have lived most of their lives in this community. Some decades ago, one of the older daughters in a family was commonly not sent to school but stayed at home instead to help the family with the daily household work (and thus stay illiterate), while the other daughters often were sent to school. A questionnaire was used to assess the sociocultural, familiar and professional background of the subjects. The questions focused on the literacy background, the reasons why the subject had (or had not) received formal schooling, the level of literacy and profession of the parents and relatives, past and present occupation of the subject, and the performance in daily life as well as occupational.

A subject is classified as illiterate if the subject has not been exposed to formal schooling (for sociocultural reasons) and has no experience of reading or writing (Reis et al., submitted). These subjects were screened to verify that they were unable to apply grapheme-phoneme associations. For example, the subjects were asked to read common words (e.g., hospital) and letter sequences (upper-/lowercase). The subjects that were unable to read and write were included in the illiterate group (the ability to sign her name was not an exclusion criterion). The literate subjects had regular reading/writing habits and received at least 4 years of formal education. These subjects were screened with a short reading/writing test, including word, sentence and text reading (aloud), test of reading comprehension, and word writing. Subjects that performed well on these tasks (fluent reading/writing and full comprehension) were included in the literate group. All subjects were screened to rule out prior disease potentially involving the brain with a clinical questionnaire. To rule out dementia or other forms of neuropsychological dysfunction a test battery developed in our laboratory was used (Garcia \& Guerreiro, 1983). This battery defines group specific norms for the subtests, including a simple oral naming task (real objects, colors, and body parts), object identification, comprehension of verbal commands, repetition of words and phrases, semantic verbal fluency, limb and oral praxis, general knowledge, memory tasks (digit span, episodic memory, and verbal memory with interference), oral calculation and tests for neglect disorders (see also Reis et al., submitted). The illiterate group consisted of 20 illiterate females subjects between ages 57 and 72 (mean $65.9 \pm 3.9$ ) and the literate included 20 literate females between ages 56 and 73 (mean $63.5 \pm 4.9)$ and a mean literacy level of $5.7 \pm 2.7$ years of education. The mean age difference was not significant $(p=.11)$.

\section{Task Procedures}

Each subject was tested in two blocks, in block 1, three different sets of items were randomly chosen without replacement to be presented in one of the presentation modes (PM): D, P, or O. Block 2 was 
included to assess learning effects (cross presentation mode priming). The same three sets used in block 1 were used in block 2, presented in a different PM compared to block 1 (e.g., block 1 , set $1-\mathrm{D}$, set $2-\mathrm{P}$, set 3-O; block 2 , set 3-P, set $1-\mathrm{O}$, set $2-\mathrm{D})$. The presentation order was identical for each group in both blocks but randomized among subjects. Before the experiment started, using a specific set of items (D, P, and O) for practice, each subject was familiarized with all experimental procedures until a satisfactory understanding of the paradigm was achieved. The subjects were instructed to attentively view each item displayed on the computer screen (or in the presentation box), name the presented item as fast and accurately as possible using the most appropriate noun, or otherwise remain silent. After the experiment a postexperiment interview was conducted with each subject to investigate the reasons for incorrect responses (e.g., visual recognition error or lexical naming error) or response failure (e.g., no visual recognition or no lexical access). During the interview, the items corresponding to erroneous responses were presented again (same PM and order in which the failures occurred), and the subject was asked to name the items (no time constraints). If the subject still did not identify the item correctly, and to differentiate the reasons for the errors made (cf. below), a semantic cue (same for all subjects) was provided in a responsive naming task. The responses obtained in this way were not included in the performance analysis but only used in the qualitative error analysis.

\section{Criteria for the Performance Analysis: Quantitative and Qualitative Analysis}

Responses were classified according to if the subject responded with a noun, independent of response accuracy (very few responses occurred outside the response window). (1) The responses were considered correct if the noun used belonged to the set of conventional names: (a) all of the conventional designations for a given object were accepted (e.g., some objects have more than one conventional designation; apito/ assobio; sino/esquila); (b) in some cases the stimuli were composed of more than one component for which a name could be used, for example, castiçal or palmatória (candlestick) for vela (candle in a candlestick) was accepted; (c) for the three compounds carro de linhas, chave de parafusos, and escova de dentes, the responses linhas, escova, and chave, respectively, were considered correct. (2) The responses were considered incorrect when the response did not correspond to any of the conventional names. (3) The absence of a response was classified as a no answer (NA). Thus there were three possible responses: correct (scored 1), incorrect, or no response (both scored 0 ).

In the qualitative error analysis, the incorrect responses and the NAs were investigated to determine their possible origin. The following criteria for error classification were used: (1) The incorrect responses were subclassified according to (1.1) visual recognition error (VRE), for example, instead of agulha (needle) the subject responded caneta (pen); (1.2) lexical naming error (LNE): the subject recognized the item but responded with an incorrect name. Two types were considered: (a) Semantically related (SR) lexical naming error, when there was an explicit semantic or visuosemantic relation between the target and the response [e.g., colar (necklace)-pulseira (bracelet); boné (cap)-chapeu (hat); parafuso (screw)-prego (nail)]; (b) not a semantically related (nSR) lexical naming error, that is, all the lexical errors that were not possible to classify as visual recognition errors or semantic associations between the response and target [e.g., botão (button) and boné (cap)]; and (1.3) Other. (2) The NAs were classified in two subtypes: (2.1) No visual recognition (NVR): When the subject did not recognize the item, even after a prolonged exposure, and used a word corresponding to a visually similar object, but was able to find the correct name when a semantic cue was given; or (2.2) no lexical access (NLA): The NA were considered as a lexical access failure when the subject spontaneously named the object correctly and commented that she knew what the object was but could not access the name during the item presentation. A similar classification was used by Newcombe et al. (1971).

\section{RESULTS}

Before the statistical analysis was undertaken we calculated the percentage of correct responses for each item in each presentation mode. To minimize the potential effects of the quality or visual information of the presented items (e.g., needle) or the frequency of encounter in daily life (e.g., screw-nut), the responses on items for which more than $50 \%$ of the subjects in both groups made incorrect responses in one presentation mode were excluded from further analysis (10 items were excluded altogether). The responses from the three sets were pooled across each PM and not analyzed separately. 

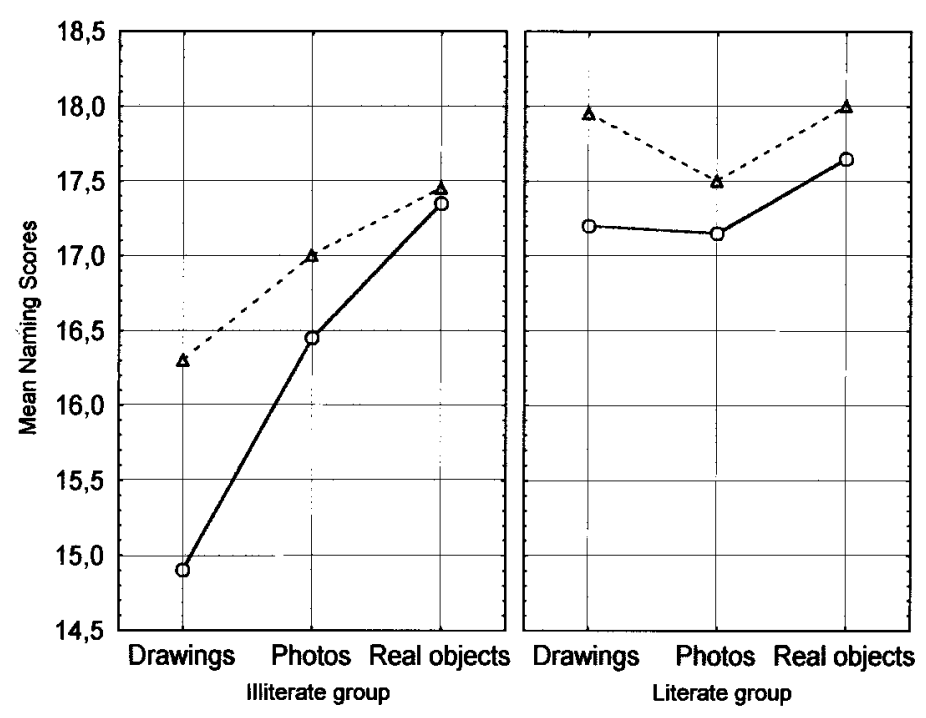

\section{- First block Second block}

FIG. 1. Plot of mean naming scores.

\section{Accuracy Analysis}

We calculated the total scores of correct answers for each subject, block, and PM, and the data were first analyzed with a nested repeated-measures mixed-effects ANOVA [considering all the factors of the experimental design, i.e., block (1 and 2), PM (D, P, and O), literacy group, and subject (20 subjects in each literacy group); this last factor was nested within the literacy factor and considered a random effect]. The results (Fig. 1) show a significant block effect $[F(1,38)=24.5 ; p<.001]$, PM effect $[F(2,76)=20.6 ; p<.001]$, literacy effect $[F(1,38)=20.9 ; p<.001]$, and a significant interaction between PM and literacy $[F(2,76)=14 ; p<.001]$.

The significant interaction related to the fact that the PM effect was significant in the illiterate group $[F(2,38)=35.4 ; p<.001]$ in both blocks [block 1: $F(1,38)=$ $14.5 ; p<.001$; block $2: F(2,38)=3 ; p=.06]$, not significant in the literate group $[F(2,38)=2.2 ; p=.12]$ in either block (nonparametric statistics yielded fully consistent results with the ANOVA; cf. Table 1). Within-group comparisons confirmed this

\section{TABLE 1}

Accuracy Comparisons

\begin{tabular}{|c|c|c|c|c|}
\hline & \multicolumn{3}{|c|}{ Presentation mode } & \\
\hline & $\mathrm{D}$ & $\mathrm{P}$ & $\mathrm{O}$ & \\
\hline \multicolumn{5}{|l|}{ Block 1} \\
\hline Illiterate & $14.9(2.2)$ & $16.5(1.5)$ & $17.4(1)$ & $p=.0006$ \\
\hline \multirow[t]{2}{*}{ Literate } & $17.2(1.4)$ & $17.2(1.3)$ & $17.7(1.2)$ & $p=.41$ \\
\hline & $U=74.5 ; p=.0007$ & $U=150 ; p=.18$ & $U=175 ; p=.51$ & \\
\hline \multicolumn{5}{|l|}{ Block 2} \\
\hline Illiterate & $16.3(1.6)$ & $17(1.4)$ & $17.5(1.3)$ & $p=.06$ \\
\hline \multirow[t]{2}{*}{ Literate } & $18(1.2)$ & $17.5(1.5)$ & $18(1.1)$ & $p=.63$ \\
\hline & $U=86.5 ; p=.002$ & $U=166.5 ; p=.37$ & $U=163 ; p=.32$ & \\
\hline
\end{tabular}

Note. The results from the within-group (Friedman ANOVA) and the between-group comparisons (Mann-Whitney $U$ test). Means and standard deviations of the correct number of responses with $p$ values from corresponding tests. $\mathrm{PM}=$ presentation mode; $\mathrm{D}=$ drawings; $\mathrm{P}=$ Photos; and $\mathrm{O}=$ objects. 
(Wilcoxon matched pairs test; the illiterate group, block 1: D vs $\mathrm{P}, p=.01$; D vs $\mathrm{O}, p<.001 ; \mathrm{P}$ vs $\mathrm{O}, p=.02$; block 2 : $\mathrm{D}$ vs $\mathrm{O}, p=.03)$. In contrast, as noted above, there was no significant difference in the literate group. The between-group comparisons showed that the literate group performs significantly better during visual naming of drawings compared to the illiterate subjects (block 1: $p<.001$; block 2: $p=.002$ ), while this was not the case for naming photos or objects. In summary, a similar block (learning) effect was present in both groups, while the PM effect related to the literacy level.

\section{Reaction-Time Analysis}

The mean reaction times (RTs) were calculated for each subject, block, and PM. In order not to confound literacy effect with performance differences, we excluded misregistered responses (e.g., hardware/software failure or ambient noise) and RTs from incorrect or no-answers. Only RTs from correct responses were included in the analysis. For technical reasons, the RT data from two illiterate subjects are missing, and to apply a nested repeated-measures mixed-effects ANOVA (used in the accuracy analysis), the condition of equal number of subjects in the two groups has to be fulfilled. So, two literate subjects were excluded using an age matching criterion. In order to test for block and literacy effects, independent of item specific effects, the items were matched across blocks and between groups for each PM. This potentially confounds PM and item-specific effects, but makes it possible to test for block and literacy effects. The results showed a significant block effect $[F(1,34)=8.1 ; p=$ $.008], \mathrm{PM}$ effect $[F(2,68)=3.2 ; p=.048]$, and literacy effect $[F(1,34)=15.4$; $p<.001]$ and no interactions were significant (the effects were similar in both blocks). When the groups were analyzed separately, a PM effect was significant $[F(2$, $34)=3.7 ; p=.036]$ in the literate but not in the illiterate group. The literacy groups (Table 2a) differed significantly in the RTs both for drawings [block $1, F(1,34)=$ $4.4, p=.045$; block $2, F(1,34)=3.6, p=.066$ ] and for photos [block 1, $F(1$, $34)=4.3, p=.045$; block $2, F(1,34)=4.3, p=.047]$, but there was no significant difference for real objects [block $1, F(1,34)=1.2, p=.28$; block $2, F(1,34)=$ $2, p=.16]$. Since the items were not matched across PMs in the above analysis, the PM effects may reflect item specific effects. To handle this, the items were matched across PMs and between groups for each block (Table $2 \mathrm{~b}$ ). The results of this analysis indicated that there was no significant difference across PMs and no interaction between the PM and literacy. However, these results have to be qualified by the fact that few items were possible to match across PMs and groups, particularly in block 1. This may result in relatively noisy RT estimates leading to decreased sensitivity of the analysis (e.g., in the literate group a significant PM effect was observed in block 2 $[F(2,34)=3.48 ; p=.04]$ and there was indication that this effect was related to the difference between $\mathrm{D}$ and $\mathrm{O}$ naming $[F(1,17)=4.0 ; p=.062]$, i.e., the RTs on naming drawings were faster than on real object naming). The observed differences are intriguing, since the illiterate group responded faster on objects compared to drawings and photos (Fig. 2), while the opposite was the case for the literate group, when the data was pooled across blocks. In summary, the RT results show a clear literacy effect in that the illiterate respond with longer RT naming $2 \mathrm{D}$ representations but not the corresponding real objects when compared with the literate group.

\section{Qualitative Error Analysis}

Two independent observers classified the incorrect responses. One of the observers was blind to the levels of all experimental factors. Both observers classified the incor- 


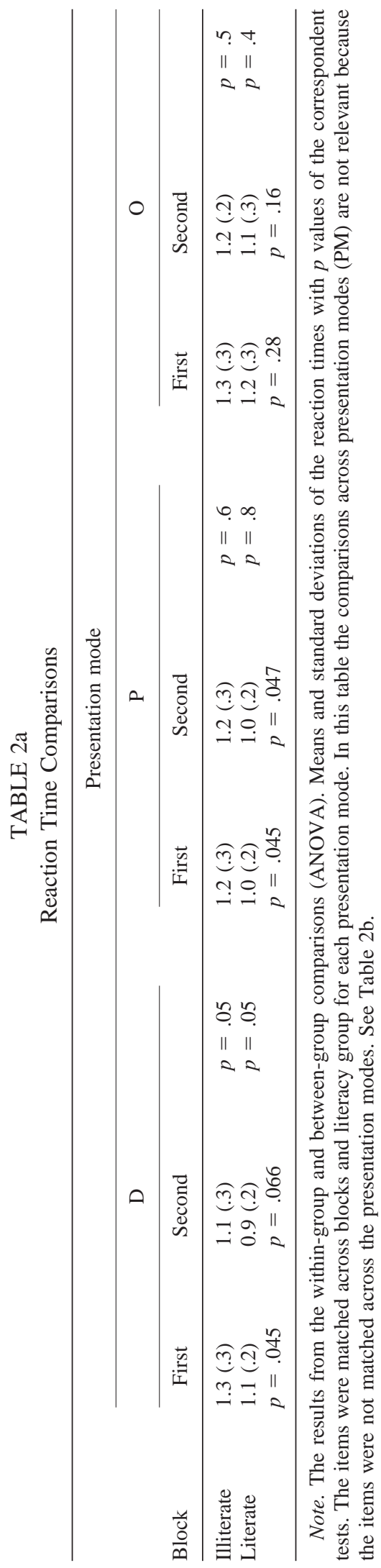




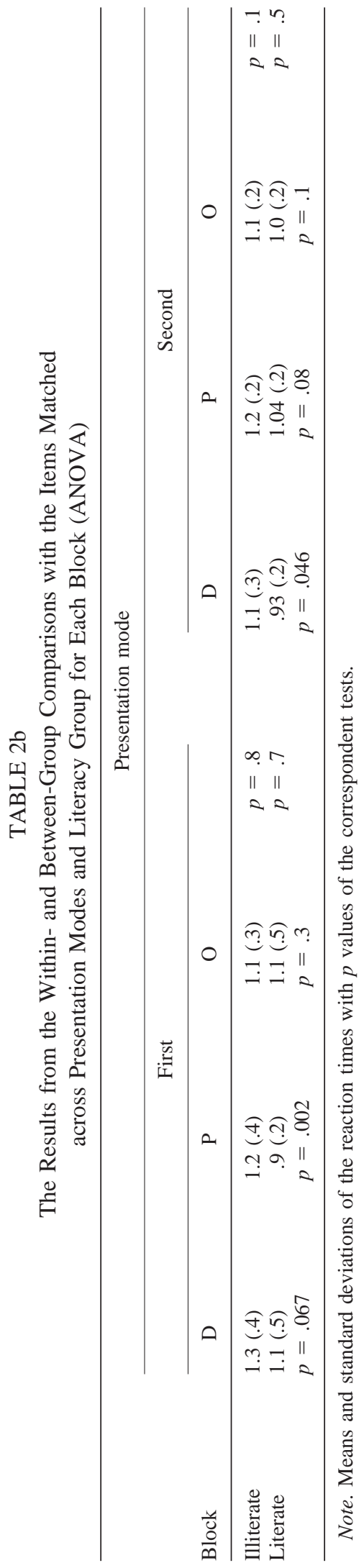


Items matched across presentation modes and literacy groups*

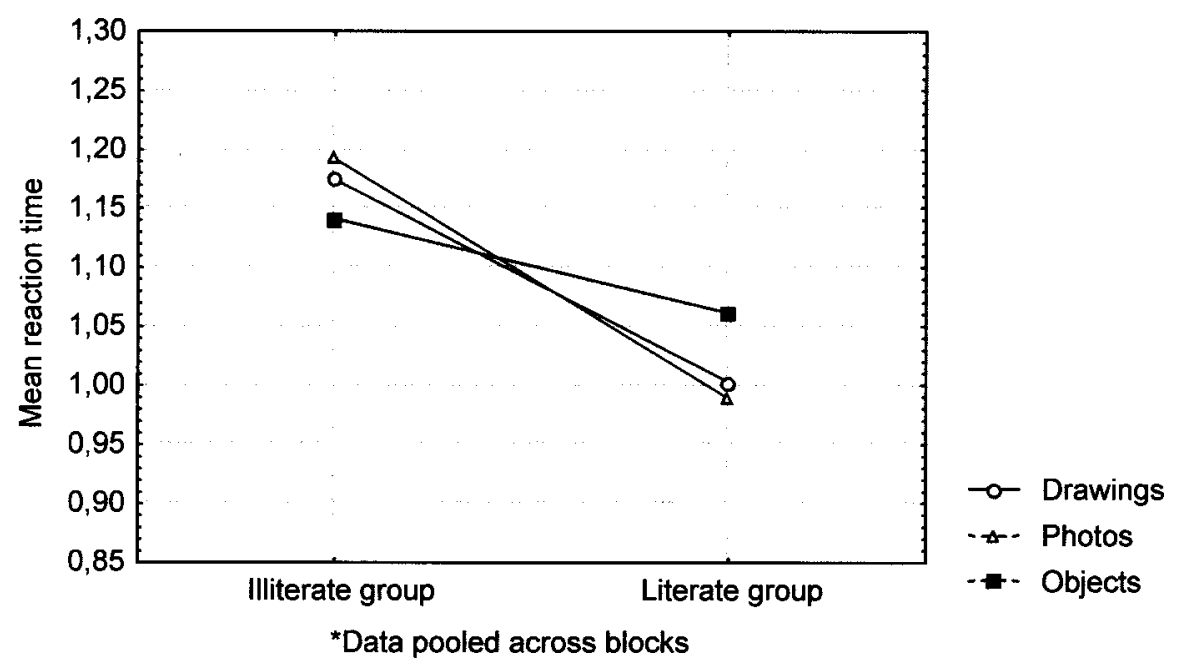

FIG. 2. Plot of mean reaction times; items are matched across presentation modes and literacy groups.

rect responses identically. We analyzed the visually related [visual recognition error (VRE) vs no visual recognition (NVR)] and the language related errors [semantically related lexical naming error (SR) vs no lexical access (NLA)]. This is similar to the approach of Newcombe et al. (1971). The other types of errors were very few (Other $=0$ in both groups; $\mathrm{nSR}$ literate $\mathrm{D} / \mathrm{P} / \mathrm{O}=0 / 1 / 1$ and $0 / 1 / 1$; illiterate $\mathrm{D} / \mathrm{P} / \mathrm{O}=0 / 1 / 0$ and $0 / 2 / 2$ in blocks 1 and 2) and were not further analyzed (cf. Appendix 2). So, we investigate whether the error patterns in the two literacy groups were different in terms of language (SR + NLA) and visually related (VRE + NVR) in each presentation mode. There were significant group differences (block 1) when naming drawings and photos $\left(\chi^{2}=3.99, p=.04 ; \chi^{2}=8.59, p=.003\right)$, while there was no significant difference during real object naming $\left(\chi^{2}=.65, p=.61\right.$; the group differences were similar in block 2 ). In summary, the visually related errors dominated in the illiterate group while the language related errors dominated in the literate group during naming of drawings, while there was no significant group difference in the error pattern naming real objects.

\section{DISCUSSION}

In this study we investigated the hypothesis that the level of literacy influences the ability to name $2 \mathrm{D}$ representations of real objects but not the corresponding real

TABLE 3

Percentage of the Total Number of Errors for Each Presentation Mode and Block

\begin{tabular}{|c|c|c|c|c|c|c|}
\hline & \multicolumn{3}{|c|}{ Illiterates } & \multicolumn{3}{|c|}{ Literates } \\
\hline & $\mathrm{D}$ & $\mathrm{P}$ & $\mathrm{O}$ & $\mathrm{D}$ & $\mathrm{P}$ & $\mathrm{O}$ \\
\hline \multicolumn{7}{|c|}{ Block 1} \\
\hline Language errors & 32 & 43 & 95 & 54 & 80 & 92 \\
\hline Visual errors & 68 & 55 & 5 & 46 & 15 & 0 \\
\hline \multicolumn{7}{|c|}{ Block 2} \\
\hline Language errors & 48 & 46 & 78 & 75 & 79 & 83 \\
\hline Visual errors & 52 & 48 & 11 & 25 & 14 & 0 \\
\hline
\end{tabular}


objects. To this end we characterized the immediate visual naming skills of literate and illiterate subjects living in a socioculturally homogeneous fishermen community of southern Portugal. The results of the present study indicate that the illiterate have lower naming scores compared to literate subjects when naming visually presented drawings of common everyday objects (and to a lesser extent photos). In contrast, there was no significant difference between the two literacy groups when naming the corresponding real objects. The analysis of the reaction times of the correct responses also demonstrated a significant literacy effect. In particular, the illiterate subjects responded with a longer mean reaction time when they correctly named drawings and photos compared to the literate group, while this was not the case when naming the real objects. Both groups showed comparable learning effects (in terms of accuracy and reaction times). It should be noted that the reaction time results should be interpreted from a different perspective compared to the accuracy data and the error analysis. While the accuracy data indicate the level of success of the recognition/ naming process and the error analysis gives qualitative information concerning the error patterns, the reaction times indicate how fast the cognitive systems are in correct information processing.

Several variables are known to influence the performance on naming tasks, including age of acquisition, object familiarity, word frequency, and imageability (Hodgson and Ellis, 1998). It is unlikely that the group differences reported in the present study are related to these variables, since the two literacy groups were well matched for age and sociocultural background. In addition, the performance on real object naming was similar, both in terms of response accuracy, response times, and error pattern in the two groups. Instead, we suggest that a more likely explanation relate to the fact that the illiterate subjects have received no formal education and lack orthographic knowledge. In the population investigated in this study, the acquisition and practice of the skill to analyze and decode 2D information most often occurred simultaneously with learning to read and write during school attendance. The lack of formal education implies that the illiterate subjects never had the opportunity to systematically learn and practice to process conventional 2D information. In addition, regular reading and writing habits improve the 2D visual skills (e.g., scanning 2D representations/ $2 \mathrm{D}$ pattern recognition). We therefore suggest that literacy, entailing the acquisition and subsequent practice in processing 2D information, modulates the skill of naming 2D representations of real objects but has a limited effect on real object naming.

Visual object naming depends on visual information processing, including shape perception, access to previously acquired visual and semantic knowledge, for visual recognition, access to the mental lexicon, and finally, the articulatory organization of verbal output. Similar cognitive skills are necessary for reading and writing (Patterson and Lambon Ralph, 1999). In this context it may be noted that it has been suggested that the analysis of shape information is fundamental for successful visual object recognition (Bierderman and Ju, 1988; Dickinson, 1999; Singh and Hoffman, 1997). Literate subjects, with regular reading and writing habit, continuously practice these skills on 2D material. This explains why the literate group performed equally well in terms of accuracy when naming drawings, photos, or real objects. In contrast, in the order of drawings, photos, and real objects, the illiterate subjects showed increasing performance accuracy, performing at a similar level on real objects as the literate group. Consistently, there was no significant group difference when naming real objects but there was a significant group difference naming drawings. The illiterate group also demonstrated longer response latencies compared to the literate group when correctly naming drawings and photos, while this was not observed when naming real objects. The absence of group differences when successfully naming real objects indicated that the reaction time differences on drawings and photos is not 
simply related to slower language processing in general. Instead, the longer processing time may be related to the processing of visual information. This would indicate that the visual processing necessary for $2 \mathrm{D}$ object recognition is in some sense different in illiterate compared to literate subjects. Alternatively, the longer response latencies may be related to the interaction between the visual and the language system. In other words, the interface between the two systems may not be so effective in handling the necessary information transfer in the illiterate as in the literate subjects. This influence of literacy, essentially reflected in 2D naming, may relate to a greater ability of the literate group to discriminate 2D shape information and support a role for experience in object representation and recognition (Wallis \& Bulthoff, 1999). An interesting observation in this study is that the illiterate group improves the performance during naming of photos in terms of accuracy but not in terms of response time. According to Bierderman and Ju (1988) information of surface-based attributes (e.g., colors, texture, and shading) only contributes to the visual recognition process when edge-based recognition is inefficient. Specifically, the added information of surface-based attributes in photos (compared to line drawings) may explain the performance increase observed in the illiterate group. In this context, the observation that the reaction times were faster when correctly naming drawings compared to real objects in the literate group may be of some interest (Fig. 2; this was observed in both blocks, though significant only in the second).

The pattern of errors made during the different naming tasks also provides clues to which part of the cognitive network is differentially affected in the literate and illiterate groups. In neuropsychological research on clinical populations, visually related errors have been associated with poor functioning of the visual recognition system, while language related errors indicate a disruption of the language network involved in the naming task. Evidence from patients with visual agnosia also indicates that the visual characteristics of the stimuli (e.g., drawings/photos vs objects) have an influence on the error pattern during visual naming (Davidoff and De Blesser, 1993; Newcombe et al., 1971). Patients that dissociate in performance on drawings vs objects producing mostly visual errors indicate a deficit in the visual recognition system, and if additional perceptual information is provided the performance improve significantly. Specifically, they name visually presented real objects significantly better than photographs or line drawings. In contrast, patients that show no picture vs object difference produce mostly semantically related errors, indicating a deficit in language processing (Davidoff and De Blesser, 1993).

In the qualitative error pattern analysis, we compared the distribution of visually and language related errors, and these distributions were significantly different in the two literacy groups for drawings and photos but not for real objects. The illiterate subjects made relatively more visually related compared to language related errors, while the pattern was the opposite for the literate group. Overall the illiterate subjects demonstrated a relatively marked pattern of visually related errors, reflecting a difficulty in the analysis and interpretation of $2 \mathrm{D}$ information that was not present during real object naming. Both literacy groups made few visually related errors during real object naming. The result of the error analysis is consistent with the reaction time results, also indicating that the inferior performance on $2 \mathrm{D}$ visual naming in illiterate subjects appears to be related to the visual system or the interface/interaction between the visual and the language systems. Taken together this interpretation is consistent with a recent suggestion that orthographic knowledge is an integral component of the general visual processing system (Patterson and Lambon Ralph, 1999), indicating that the acquisition of a written language may affect specific parts of the visual system. Interestingly, a positive correlation between reading abilities and the capacity to name line drawings have also been reported (Goldblum \& Matute de Duran, 1986). 
In this context, this correlation may be related to the fact that decoding and interpretation of 2D representations is significantly more practiced in literate compared to illiterate subjects.

In summary, it seems difficult to explain the $2 \mathrm{D}$ visual naming accuracy problems and the slower response times on correct $2 \mathrm{D}$ visual naming and that the visually related errors dominate when the illiterate subjects name drawings of real objects, as a general lexical access or retrieval problem. Especially in conjunction with the limited differences between the two literacy groups when naming real objects. Instead, we suggest that the visual system in a wide sense (including, e.g., visual attention) and/or the interface between the visual and the language systems are differently formatted in literate and illiterate subjects reflecting the different experience in acquisition and practice in interpreting and producing 2D representations of information.

Finally, we have previously indicated that the pattern of interactions between brain regions of a functional-anatomic language network differ in literate and illiterate subjects during immediate verbal repetition of pseudowords (Petersson et al., 2000). Given that the neuroanatomical architecture of the brain resembles a hierarchically structured, recurrently connected network (Shepherd, 1997) and the hypothesis that information processing, subserving complex cognitive brain functions, results from the interactions between functionally specialized neural groups or brain regions (Amit, 1989; Arbib, 1995), we suggest that the interactions within and between the visual and language processing networks of the brain may differ in literate and illiterate subjects. Further investigations of these issues in behavioral and functional neuroimaging studies, in combination with a network approach to the functional architecture of the brain (Ingvar and Petersson, 2000), is necessary for a more complete understanding of the differences between the literate and illiterate subjects reported here.

\section{CONCLUSIONS}

The modulatory influence of literacy has been indicated in behavioral, functional neuroimaging, and neuroanatomical studies (Petersson et al., 2001). In this study we explored the functional consequences of formal education and the acquisition of alphabetic orthographic knowledge on $2 \mathrm{D}$ and $3 \mathrm{D}$ visual naming. The results suggest that formal education and learning to read and to write as well as the subsequent practice associated with these skills, modulate the cognitive systems involved in naming $2 \mathrm{D}$ representations of real objects. Both the results of the reaction time and the error pattern analyses can be interpreted as indicating that the major influence of literacy affects the visual system or the interaction between the visual and the language systems. We suggest that the visual system in a wide sense and/or the interface between the visual and the language system are differently formatted in literate and illiterate subjects. However, the details of the modulatory influence of literacy and orthographic knowledge on the functional architecture of the brain generally and in particular on the visual naming skills is still not well understood but the subject of ongoing research. 


\section{APPENDIX 1}

The Item Set Selected from Snodgrass and Vanderwart (1980)

\begin{tabular}{|c|c|c|c|}
\hline \multicolumn{2}{|l|}{ Portuguese name } & \multicolumn{2}{|l|}{ English name } \\
\hline agulha & prego & needle & nail \\
\hline alicate & regador & pliers & watering-can \\
\hline anel* & régua & ring & ruler \\
\hline apito & relógio & whistle & watch \\
\hline bola & rolo & ball & rolling-pin \\
\hline boné & saleiro* & cap & saltshaker \\
\hline botão* & sapato & button & shoe \\
\hline cabide & sino & hanger & bell \\
\hline cachimbo & tesoura & pipe & scissors \\
\hline cadeado & tigela & padlock & bowl \\
\hline caixa & vela & box & candle \\
\hline caixote* & & chest (dust bin) & \\
\hline caneta & Treino & pen & Training \\
\hline carro de linhas & telefone & thread car & phone \\
\hline cesto & flôr & basket & flower \\
\hline chapéu & pilha & hat & pile \\
\hline chave & planta & key & plant \\
\hline chave de parafusos* & pêssego & screw-driver & peach \\
\hline chavena & limão & cup & lemon \\
\hline cigarro & pera & cigarette & pear \\
\hline cinto & maçã & belt & apple \\
\hline cinzeiro & laranja & ash-tray & orange \\
\hline colar & chapéu de marinheiro & necklace & sailor hat \\
\hline colher & & spoon & \\
\hline copo & & glass & \\
\hline corrente & & chain & \\
\hline dedal & & thimble & \\
\hline envelope & & envelope & \\
\hline escova & & brush & \\
\hline escova de dentes & & tooth-brush & \\
\hline faca & & knife & \\
\hline ferro & & iron & \\
\hline ficha* & & plug & \\
\hline frigideira & & frying-pan & \\
\hline garfo & & fork & \\
\hline garrafa & & bottle & \\
\hline gravata & & tie & \\
\hline interruptor* & & switch & \\
\hline jarro & & water-jar & \\
\hline lâmpada & & lamp & \\
\hline lápis & & pencil & \\
\hline lima* & & nail-file & \\
\hline livro & & book & \\
\hline luva & & glove & \\
\hline maçaneta* & & door handle & \\
\hline martelo & & hammer & \\
\hline mola & & peg & \\
\hline óculos & & eye-glass & \\
\hline parafuso & & screw & \\
\hline pente & & comb & \\
\hline peúgo & & sock & \\
\hline pincel & & paintbrush & \\
\hline pistola & & pistol & \\
\hline porca* & & nut & \\
\hline
\end{tabular}

Note. Items marked with an asterisk were eliminated. 
APPENDIX 2

Frequency of Error Data for Each Presentation Mode and Block

\begin{tabular}{|c|c|c|c|c|c|c|}
\hline & \multicolumn{6}{|c|}{ Presentation mode } \\
\hline & \multicolumn{3}{|c|}{ Illiterate group } & \multicolumn{3}{|c|}{ Literate group } \\
\hline & $\mathrm{D}$ & $\mathrm{P}$ & $\mathrm{O}$ & $\mathrm{D}$ & $\mathrm{P}$ & $\mathrm{O}$ \\
\hline \multicolumn{7}{|c|}{ Block 1} \\
\hline SR & 20 & 10 & 17 & 7 & 13 & 6 \\
\hline NLA & 4 & 8 & 1 & 6 & 3 & 6 \\
\hline VRE & 29 & 10 & 1 & 10 & 0 & 0 \\
\hline NVR & 23 & 13 & 0 & 1 & 3 & 0 \\
\hline $\mathrm{nSR}$ & 0 & 1 & 0 & 0 & 1 & 1 \\
\hline Other & 0 & 0 & 0 & 0 & 0 & 0 \\
\hline \multicolumn{7}{|c|}{ Block 2} \\
\hline SR & 16 & 15 & 13 & 9 & 6 & 3 \\
\hline NLA & 3 & 0 & 1 & 0 & 5 & 2 \\
\hline VRE & 16 & 9 & 2 & 3 & 2 & 0 \\
\hline NVR & 5 & 7 & 0 & 0 & 0 & 0 \\
\hline nSR & 0 & 2 & 2 & 0 & 1 & 1 \\
\hline Other & 0 & 0 & 0 & 0 & 0 & 0 \\
\hline
\end{tabular}

\section{REFERENCES}

Amit, D. J. (1989). Modeling brain function: The world of attractor neural networks. Cambridge, UK: Cambridge Univ. Press.

Arbib, M. A. (1995). The handbook of brain theory and neural networks. Cambridge, MA: MIT Press.

Ardila, A., Rosselli, M., \& Rosas, P. (1989). Neuropsychological assessment in illiterates: Visuospatial and memory abilities. Brain and Cognition, 11, 147-166.

Bierderman, I., \& Ju, G. (1988). Surface versus edge-based determinants of visual recognition. Cognitive Psychology, 20, 38-64.

Castro-Caldas, A., Miranda, P., Carmo, I., Reis, A., Leote, F., Ribeiro, C. et al. (1999). Influence of learning to read and write on the morphology of the corpus callosum. European Journal of Neurology, 6, 23-28.

Castro-Caldas, A., Petersson, K. M., Reis, A., Stone-Elander, S., \& Ingvar, M. (1998). The illiterate brain: Learning to read and write during childhood influences the functional organisation of the adult brain. Brain, 121, 1053-1063.

Davidoff, J., \& De Blesser, R. (1993). Optic aphasia: A review of the past studies and reappraisal. Aphasiology, 7, 135-154.

Dickinson, S. J. (1999). Object representation and recognition. In E. Lepore \& Z. Pylyshyn, (Eds.), What is cognitive science? Oxford, UK: Blackwell.

Goodglass, H., Theurkauf, J. C., \& Wingfield, A. (1984). Naming latencies as evidence for two nodes of lexical retrieval. Applied Psycholinguistics, 5, 135-146.

Hodgson, C., \& Ellis, A. W. (1998). Last in, first to go: Age of acquisition and naming in the elderly. Brain and Language, 64, 146-163.

Ingvar, M., \& Petersson, K. M. (2000). Functional maps and brain networks. In A. W. Toga \& J. C. Mazziotta (Eds.), Brain mapping: The systems. San Diego: Academic Press.

Kremin, H., Deloche, G., Metz-Lutz, M.-N. et al. (1991). The effect of age, educational background and sex on confrontation naming in normals: Principles for testing naming ability. Aphasiology, 5, 579-582.

Levelt, W. J. M., Praamstra, P., Meyer, A. S., Helenius, P., \& Salmelin, R. (1998). An MEG study of picture naming. Journal of Cognitive Neuroscience, 10, 553-567.

Manly, J. J., Jacobs, D. M., Sano, M., Bell, K., Merchant, C. A., Small, S. A. et al. (1999). Effect of literacy on neuropsychological test performance in nondemented, education-matched elders. Journal of International Neuropsychological Society, 5, 191-202. 
Matute, E., Leal, F., Zarabozo, D., Robles, A., \& Cedillo, C. (2000). Does literacy have an effect on stick construction tasks? Journal of International Neuropsychological Society, 6, 668-672.

Newcombe, F., Oldfield, R. Ratcliff, G. G., \& Wingfield, A. (1971). Recognition and naming of objectdrawings by men with focal brain wounds. Journal of Neurology, Neurosurgery, and Psychiatry, 34, 329-340.

Ostrosky, F., Efron, R., \& Yund, E. W. (1991). Visual detectability gradients: Effect of illiteracy. Brain and Cognition, 17, 42-51.

Patterson, K., \& Lambon Ralph, M. A. (1999). Selective disorders of reading? Current Opinion in Neurobiology, 9, 235-239.

Petersson, K. M., Reis, A., Askelöf, S., Castro-Caldas, A., \& Ingvar, M. (2000). Language processing modulated by literacy: A network analysis of verbal repetition in literate and illiterate subjects. Journal of Cognitive Neuroscience, 12, 364-382.

Petersson, K. M., Reis, A., Askelöf, S., Castro-Caldas, A., \& Ingvar, M. (1998). Differences in interhemispheric interactions between literate and illiterate subjects during verbal repetition. NeuroImage, 7, S217.

Petersson, K. M., Reis, A., \& Ingvar, M. (2001). Cognitive processing in literate and illiterate subjects: Some recent behavioral and functional neuroimaging data. Scandinavian Journal of Psychology, 42, 251-267.

Reis, A., \& Castro-Caldas, A. (1997). Illiteracy: A bias for cognitive development. Journal of International Neuropsychological Society, 3, 444-450.

Reis, A., Guerreiro, M., \& Castro-Caldas, A. (1994). Influence of educational level of non brain-damaged subjects on visual naming capacities. Journal of Clinical and Experimental Neuropsychology, 16, 939-942.

Reis, A., Guerreiro, M., \& Petersson, K. M. (submitted) A socio-demographic and neuropsychological characterization of an illiterate population.

Rosselli, M., Ardila, A., \& Rosas, P. (1990). Neuropsychological assessment in illiterates. II. Language and praxic abilities. Brain and Cognition, 12, 281-296.

Salmelin, R., Hari, R., Lounasmaa, O. V., \& Sams, M. (1994). Dynamics of brain activation during picture naming. Nature, 368, 463-465.

Shepherd, G. M. (1997). The synaptic organization of the brain. New York: Oxford Univ. Press.

Singh, M., \& Hoffman, D. D. (1997). Constructing and representing visual objects. Trends in Cogitive Sciences, 1, 98-102. 